\title{
A potential benefit from infectious disease specialist and stationary ward in rational antibiotic therapy of complicated skin and skin structure infections
}

\section{Jääskeläinen, liro H.}

2018

Jääskeläinen , I H , Hagberg , L , Schyman , T \& Järvinen , A 2018 , ' A potential benefit from infectious disease specialist and stationary ward in rational antibiotic therapy of complicated skin and skin structure infections ', Infectious Diseases, vol. 50 , no. 2 , pp. 107-116 . https://doi.org/10.1080/23744235.2017.1362706

http://hdl.handle.net/10138/311579

https://doi.org/10.1080/23744235.2017.1362706

acceptedVersion

Downloaded from Helda, University of Helsinki institutional repository.

This is an electronic reprint of the original article.

This reprint may differ from the original in pagination and typographic detail.

Please cite the original version. 


\section{A potential benefit from infectious disease specialist and stationary ward in rational antibiotic therapy of complicated skin and skin structure infections}

liro H Jääskeläinen ${ }^{1}$, Lars Hagberg², Tommy Schyman ${ }^{3}$ Asko Järvinen ${ }^{1}$

${ }^{1}$ Department of Infectious Diseases, Inflammation Center, Helsinki University Central Hospital and Helsinki University, Helsinki, Finland

${ }^{2}$ Institute of Biomedicine, Department of Infectious Diseases, Sahlgrenska Academy, University of Gothenburg, Sweden

${ }^{3}$ TFS, Lund, Sweden

Corresponding Author: liro Jääskeläinen, Helsinki University Central Hospital, Department of Infectious Diseases, PL 348, 00029 HUS, Helsinki, Finland; E-mail: iiro.jaaskelainen@hus.fi; Tel: +358 50 4271509; FAX: +358947175900

The length of abstract 250 words, the length of manuscript 3245 words. 


\begin{abstract}
Background

Management practices of complicated skin and skin structure infections (cSSSI) were compared between two areas with similar healthcare structure and low prevalence of antimicrobial resistance.
\end{abstract}

\title{
Methods
}

The high affinity to public health-care in the Nordic countries enabled population-based approach used in this retrospective study. The study population $(n=460)$ consisted of all adult residents from Helsinki (Finland) and Gothenburg (Sweden) treated in hospital due to cSSSI during $2008-2011$.

\section{Results}

The majority of patients in Helsinki (57\%) visited more than one ward during their hospital stay while in Gothenburg the majority of patients (85\%) were treated in one ward only. Background and disease characteristics were largely similar in both cities but patients in Helsinki were younger [mean(SD) 59(18) versus 63(19) years, $p=0.0117$ ], and greater proportions had diabetes (50\% versus $32 \%, p<0.0001)$ and polymicrobial infections (34\% versus $13 \%, p<0.0001)$. Patients in Helsinki received antimicrobials with Gram-negative coverage (in initial therapy 96\%) more frequently than in Gothenburg $(47 \%, p<0.0001)$, had more treatment modifications (mean 4.3 versus 2.7 antibiotic agents used per patient, $p<0.0001$ ), and longer median duration of antimicrobial therapy (29 versus 12 days, $p<0.0001)$ and median length of hospital stay (17 versus 11 days, $p<0.0001)$.

\section{Conclusions}

This real-life study revealed remarkable differences in the management of cSSSI between the two Nordic cities. Compared to mainly Infectious Disease Specialist guided treatment in Gothenburg, the more frequent transfer from one ward to another in Helsinki was linked to longer antimicrobial therapy and hospital stay and to more frequent changes in antimicrobial treatment. 


\section{Introduction}

Skin and skin structure infections (SSSIs) are a common and a rapidly increasing reason for hospitalization [1,2]. SSSI is generally considered as complicated (cSSSI) if it involves deep subcutaneous tissues or needs surgery in addition to antimicrobial therapy [3]. SSSI can also be classified as complicated if it affects a patient with significant underlying co-morbidities like diabetes or peripheral vascular disease. Streptococci and Staphylococcus aureus are the most common causative agents in SSSIs but in complicated cases Gram-negative rods and anaerobic bacteria may also play a role [4-7].

There are many antimicrobial therapies available for SSSI and antibiotic treatments from penicillin to broad-spectrum combinations have been recommended in guidelines [8-10]. A cohort study suggested that inappropriately broad-spectrum antibiotics were used in the milder SSSIs and that the most severe cSSSIs were treated with insufficient antimicrobial coverage [11]. Inappropriate empirical antimicrobial therapy was also associated with longer length of stay and higher total costs [12]. In addition to the variation in antimicrobial therapies used, notable variability in the treatment duration of cSSSI has been reported [13-17].

Finland and Sweden are countries with a low prevalence of methicillin resistant Staphylococcus aureus (MRSA, in 2011: Finland 2.8\%, Sweden 0.8\%) in contrast to many other European countries $[18,19]$. Therefore, antibiotics with MRSA-coverage are not recommended for the empirical treatment of SSSI in the national guidelines [20,21]. Yet, differences exist between the national guidelines of Finland and Sweden, especially in the suggested duration of antimicrobial treatment for uncomplicated erysipelas/cellulitis which is $14-21$ days in Finland and $10-14$ days in Sweden $[20,21]$.

Finland and Sweden share high affinity to public health care which enables comparison of treatment practices in comprehensive populations of patients with cSSSI. In the primary analysis of the study data [22], we observed great differences in the characteristics and treatment practises of cSSSI between two Nordic cities, Helsinki in Finland and Gothenburg in Sweden. The aim of this 
retrospective real-life study was to further evaluate the factors behind the differences between countries may offer means to optimize the antimicrobial treatment and clinical management of cSSSI.

\section{Methods}

The inclusion and exclusion criteria of this observational retrospective cohort study are described in detail in the primary publication of this study [22]. The study population consisted of all adult residents who were treated in hospital because of cSSSI during $2008-2011$ from cities with nearly equal size of population (Helsinki, Finland, population of 588000 and the Gothenburg area, Sweden, population 600 000). For patient case finding, first selection was made from hospital databases by certain ICD10 diagnostic codes. Inclusion criteria to the final analysis population were an infection requiring significant surgical intervention, affecting deeper soft tissue, developed on a lower extremity in a subject with diabetes mellitus or peripheral vascular disease, or a major abscess or infected ulcer. Patients also had to have at least one systemic sign of infection: body temperature of $>38$ or $<36^{\circ} \mathrm{C}$, or white blood cell count of $>10,000 / \mathrm{mm}^{3}$ or $<4,000 / \mathrm{mm}^{3}$.

Infection was defined as health-care associated if the patient had been hospitalized or had undergone invasive surgery within previous three months. Cellulitis/fasciitis was defined as no abscess, diabetic foot/leg ulcer or peripheral vascular ulcer. The evaluation of clinical stability was based on improvement of vital signs and decreased fever in addition to local signs of infection. Treatment failure was defined as need for unplanned surgery, no improvement in clinical situation after 5 days of treatment, or treatment failure registered in patient records by treating physician. Data for evaluation of recurrences and mortality were collected 1-year post-cSSSI diagnosis.

To enable comparison between cities, patients treated in Helsinki City hospital were combined into the clinic of Medicine and treatment at Home hospital (Helsinki) was regarded as home-based care; but since the Home hospital had treatment facilities similar to in-patient treatment (e.g. 
intravenous antibiotics), the treatment was included to the total length of hospital stay. Homebased care included follow up of cure, wound care or other forms of nursing.

Categorical variables were summarized using counts and percentages. The Fischer's exact test and Cochran-Mantel-Haenszel statistics, controlling for age, were utilized in the statistical analyses of categorical variables. Continuous variables were summarized using means, standard deviation, median, first and third quartile, min and max values. For continuous variables, a two sample t-test or the analysis of variance (ANOVA) were used to test for difference between two subgroups and if assumption of normal distribution was violated, also Wilcoxon rank-sum test was used.

\section{Results}

\section{Patient population and baseline characteristics}

1164 patients in Helsinki and 2151 in Gothenburg with possible SSSI were identified by hospital discharge ICD10-codes, of which 219 and 241 patients, respectively, met the inclusion criteria for cSSSI. In Helsinki, 191 patients were included from Helsinki University Central Hospital and 28 from Helsinki City Hospital; in Gothenburg all patients were from Sahlgrenska University Hospital. The average annual incidence of cSSSI within the study period was 9/100,000 in Helsinki and $10 / 100,000$ in Gothenburg. Compared to patients in Gothenburg, patients in Helsinki were slightly younger and had greater frequency of chronic renal failure, diabetes or a prior hospitalization (Table 1). Patients in Gothenburg were treated statistically significantly more often with antibiotics before their infection met the cSSSI criteria (Table 1).

Statistically significant differences were not found between Helsinki and Gothenburg in the proportion of patients with abnormal white blood cell count, in the peak C-reactive protein level, in the occurrence of septic shock or in the need for blood pressure support (Table 2). However, blood culture-positive infections were more common in Helsinki (18\% of patients) than in Gothenburg (9.1\% of patients, $p=0.0102)$. On average, the diagnosis of cSSSI was made later in Gothenburg in comparison to Helsinki although in both cities half of the patients were diagnosed between 2 to 7 
days after the symptoms had started (Table 2). Cellulitis and abscess were the main diagnoses, with similar proportions in both cities, but postsurgical wound infections were more common in Helsinki, whereas infected ulcers related to peripheral vascular disease or pressure were more common in Gothenburg (Table 2).

\section{Microbiological diagnosis}

Microbiological tests (i.e. bacterial culture of blood, wound or affected tissue) were taken from 97 $\%$ and $91 \%$ of patients and microbiological diagnosis was obtained in $65 \%$ and $73 \%$ of the patient population in Helsinki and Gothenburg, respectively. Staphylococci and streptococci were the most commonly isolated pathogens in both cities although in Helsinki they were found more often as one of the microbes in polymicrobial infections which were significantly more common in Helsinki (34 \% of patients) than in Gothenburg (13\%, $p<0.0001$, Table 3). In Helsinki, more patients $(23 \%)$ were without a microbiological diagnosis as compared to Gothenburg $(12 \%, \mathrm{p}<$ 0.0001). Staphylococcus aureus was the most common finding in blood cultures and accounted for $46 \%$ and $50 \%$ of the findings in Helsinki and Gothenburg, respectively.

\section{Antimicrobial therapy}

Initial antimicrobial therapy was mainly empirical in both cities although it was significantly more often classified as specific in Gothenburg (20\%) than in Helsinki $(1.8 \%, p<0.0001)$. Initial antimicrobial therapy was given intravenously in the majority of patients, in $93 \%$ and $91 \%$ of the patients in Helsinki and Gothenburg, respectively. Antimicrobial agents used in initial therapy differed significantly between cities when analysed between the main categories (broad-spectrum, cephalosporins, penicillins, penicillins with staphylococcal effect and other; $p<0.0001$, Table 5). In total, ten different agents were used in Helsinki and 20 in Gothenburg in initial therapy (Table 5). In Helsinki, initial antimicrobial therapy consisted almost exclusively of cephalosporins and broadspectrum antibiotics (carbapenems and piperacillin-tazobactam) whereas narrow-spectrum therapies (penicillins with or without staphylococcal effect) were used more often in Gothenburg (Table 5). Initial antimicrobial treatment covered cultured pathogens in $79 \%$ of the patients in Helsinki $(n=184)$ and $87 \%$ of the patients in Gothenburg $(n=169, p=0.056)$. Antibiotics with 
definitive MRSA-coverage (vancomycin, linezolid and tigecycline) were used in initial therapy in 0.5 $\%$ and $0.4 \%$ of the patients and in subsequent therapy in $7.4 \%$ and $0.5 \%$ of the patients in Helsinki and Gothenburg, respectively.

The median overall duration of antimicrobial therapy was 29 days in Helsinki and 12 days in Gothenburg ( $p<0.0001$, Table 4), and the median duration of intravenous treatment was 14 days in Helsinki and 6.5 days in Gothenburg $(p<0.0001)$. There was also a difference in the number of antibiotic changes between the cities. In Helsinki, each patient was treated in an average with 4.3 different antibiotics but in Gothenburg only 2.7 different agents per patient were used $(p<0.0001$, Table 4). Treatment was completed with the same agent that it was started with in $1.8 \%$ and $8.8 \%$ of patients in Helsinki and Gothenburg $(p=0.0015)$, respectively. Initial intravenous antibiotic treatment was modified to another intravenous drug in $55 \%$ and $31 \%$ of the patients $(p<0.0001)$ and the median time from diagnosis to the first modification was 3 and 4 days $(p=0.0507)$ in Helsinki and Gothenburg, respectively (Table 4). $77 \%$ of the patients in Helsinki and $53 \%$ in Gothenburg continued with an (mainly oral) antimicrobial agent after hospital discharge (Table 5).

\section{Clinical management and outcome}

In Helsinki the patients were treated in significantly more different wards as compared to Gothenburg (Table 4, Figure 1). In Helsinki $57 \%$ of the patients visited two or more wards during the hospital stay while in Gothenburg $85 \%$ of the patients were treated in one ward only (Table 4 and Figure 1). Treatment on a surgical ward was more common in Helsinki $(64 \%$ versus $25 \%, p=$ $0.0001)$ and treatment on an infectious disease ward was less common ( $25 \%$ versus $48 \%, p=$ 0.0001) as compared to Gothenburg (Table 4). The patients in Helsinki had more surgical interventions (64 \% of patients) after diagnosis of cSSSI than in Gothenburg (40\%, p $<0.0001)$. The median length of hospital stay was significantly longer in Helsinki than in Gothenburg (17 versus 11 days, $p<0.0001$, Table 4), but in Gothenburg, patients received more often homebased care after discharge than in Helsinki $(57 \%$ versus $32 \%, p<0.0001)$. 
The mean time from diagnosis to clinical stability was 4.4 days in Helsinki and 3.4 days in Gothenburg $(p=0.0204)$ and treatment failure was detected in $37 \%$ and $38 \%$ of the patients $(p=$ 0.8430), respectively. Within 12 months after initial discharge $16 \%$ of the patients in Helsinki and $19 \%$ in Gothenburg were hospitalized again due to SSSI in same the anatomical location ( $p=$ 0.3776). Mortality in Helsinki was significantly higher than in Gothenburg; 30 day mortality (5.5\% versus $2.1 \%, p=0.0326$ ) and 12 month mortality ( $16 \%$ versus $7.5 \%, p=0.0003$, respectively).

\section{Discussion}

This real-life study revealed remarkable differences in the treatment and management of cSSSI between two centers with similar antimicrobial resistance background. In comparison to patients in Gothenburg, patients in Helsinki were predisposed more frequently to antimicrobials with Gramnegative coverage, had more treatment modifications, longer median duration of antimicrobial therapy and length of hospital stay. In addition, the majority of patients in Helsinki visited more than one ward during their hospital stay while in Gothenburg $85 \%$ of patients were treated in one ward, most commonly in the ward of Infectious Diseases.

Strengths and limitations of our population based retrospective study are fully discussed in the primary publication of this material [22]. Evidently, there was some differences in the patient populations between the two cities although we tried to apply strict criteria for patient data collection. The baseline characteristics of the populations were quite similar (Table 1). The study groups of both cities had a male predominance and a high number of co-morbidities but patients in Helsinki were younger than in Gothenburg (mean age 59 versus 63 years, $p=0.0117$ ). Statistically significant differences were found between Helsinki and Gothenburg in the frequency of some comorbidities such as diabetes (50\% versus $32 \%)$, chronic renal failure $(11 \%$ versus $2.9 \%$ ) and respiratory disease (10\% versus $5.0 \%$ ) which were more common among patients in Helsinki but congestive heart disease ( $4.6 \%$ versus $14 \%$ ) among patients in Gothenburg, respectively. These co-morbidities have been frequently observed in patients with cSSSI also in other studies $[14,15,23]$ 
Many of the cSSSI related characteristics were almost identical in Helsinki and Gothenburg. In both cities, patients were classified to have mainly cellulitis or abscess, although post-surgical wound infections were more common in Helsinki but infected peripheral vascular disease ulcers or infected decubitus ulcers were more prevalent in Gothenburg. No significant differences were found between the study groups among the objective measures of disease severity like white blood cell count at the time of diagnosis, highest C-reactive protein level, patients with septic shock or need for blood pressure support. In both cities, the occurrence of bacteremic infections was higher than reported in previous studies which suggests that in cSSSI blood cultures should be taken more frequently than recommended in uncomplicated cellulitis $[9,13,15]$.

Staphylococcus aureus (42\% versus $43 \%$ ) and streptococci (33\% versus $31 \%$ ) were the most common pathogens both in Helsinki and in Gothenburg, respectively. The dominance of Grampositive bacteria among the causative agents is consistent with other studies made in patients with cSSSI $[15,23,24]$. However, there were significantly more polymicrobial infections in Helsinki than in Gothenburg and they were usually due to Gram-negative or anaerobic bacteria in conjunction with Gram-positive bacteria. The higher prevalence of diabetes and previous hospitalization may explain in part the higher proportion of polymicrobial infections in Helsinki, but differences in laboratory reporting practices between countries cannot be ruled out. That is, the more abundant reporting of species from the bacterial culture may encourage continuing with or changing to broad-spectrum antimicrobial therapy.

Despite the similarity of the patient and disease characteristics, striking differences were observed in clinical practices between the study centres. Based on microbiological results, Gram-negative or anaerobic bacteria were present in the minority of patients both in Helsinki (33\%) and in Gothenburg (18\%). Yet, $96 \%$ of patients in Helsinki and $47 \%$ in Gothenburg were initially treated with antibiotics covering Gram-negative bacteria. Even after the first treatment modification, $61 \%$ of patients in Helsinki and $33 \%$ in Gothenburg still received Gram-negative coverage. Coverage for Gram-negative and anaerobic bacteria in empirical treatment of SSSI is recommended by the IDSA guidelines, mainly for infections associated with diabetic foot, peripheral vascular 
insufficiency, bites, prior contact to health care and in necrotizing infections, which is consistent with the national guidelines of Finland and Sweden $[9,20,21,25]$. Although many patients in both cities belonged to these risk-groups, the majority of patients would not have needed Gramnegative coverage according to their microbiological results. It should be noted that diabetic foot/leg infections were rare and comprised only $15 \%$ of patients in both cities. In the U.S., Jenkins et al. also found similar unnecessary use of antimicrobials with Gram-negative coverage in less severe SSSI [13]. Cephalosporin-based treatment (with Gram-negative coverage) was significantly more common in Helsinki, whereas more penicillin-based therapies (without Gram-negative coverage) were used in Gothenburg. This difference in antibiotic use practices might largely explain the more common Gram-negative coverage in Helsinki. The more common cephalosporin use in cSSSI seems to reflect the general use of antimicrobials in hospital setting. In nationwide statistics in 2011 , the use of non-penicillin beta-lactam antibiotics was five times more common in Finland as compared to Sweden [26]. The broader antimicrobial use in Helsinki did not result in better coverage of the cultured pathogens with the initial antimicrobial treatment, which was $87 \%$ in Gothenburg and $79 \%$ in Helsinki $(p=0.056)$.

There were great differences in the number of different wards in which the patient was treated, in the number of modifications in the antimicrobial treatment, and in the length of hospital stay and antimicrobial treatment between the cities. In Helsinki, $57 \%$ of patients were treated in more than one ward, while in Gothenburg the majority (85 \%) of patients stayed in one ward. In Helsinki, patients were treated most frequently in the ward of Surgery, but in Gothenburg in the ward of Infectious Diseases. To the best of our knowledge, the effect of Infectious Disease Specialist based treatment on the outcome of patients with cSSSI has not been studied. Infectious Disease Specialist consultation has been shown to improve the treatment of Staphylococcus aureus bacteraemia, but in SSSI it was identified as an independent risk factor for broad-spectrum antimicrobial therapy $[27,28]$. The time from diagnosis to the first modification of intravenous antibiotic treatment to another intravenous agent was almost statistically significantly longer in Gothenburg (median 4 days) than in Helsinki ( 3 days, $p=0.0507)$. The number of different 
antibiotic courses was significantly higher in Helsinki (mean 4.3) than in Gothenburg (mean 2.7, p $<0.0001)$. The frequent transfer to another ward has probably affected to the earlier and more frequent modifications in antibiotic treatment in Helsinki.

Perhaps the most striking difference was the more than double longer total antimicrobial treatment in Helsinki than in Gothenburg. The median duration of antimicrobial therapy in Helsinki (29 days) also far exceeds the duration detected in previous studies and recommended in guidelines $[9,13,15,20]$. The national guidelines for the treatment of (mainly uncomplicated) SSSI in Finland and Sweden have different recommendations for total treatment durations, $14-21$ and $10-14$ days, respectively $[20,21]$. The IDSA-guideline suggests a treatment duration of 5 days if clinical improvement has occurred, based on study of patients with uncomplicated cellulitis $[9,29]$.

The patient population in Helsinki was more severely sick than that in Gothenburg. There were more bacteraemic cases in Helsinki, and half of the patients in Helsinki had diabetes, as compared to one third in Gothenburg. The 30-day mortality in Helsinki (5.5\%) was higher than in Gothenburg $(2.1 \%, p=0.0326)$. These mortalities fall within the range from $0.4 \%$ to $9.0 \%$ that has been previously reported for cSSSI $[11,14,23,30]$. In comparison to Helsinki, the average time to clinical stability was significantly shorter (3.4 versus 4.4 days) and significantly less clinical failures due to no change or worsened clinical situation after 5 days of treatment ( $8.3 \%$ versus $17 \%$ ) were detected in Gothenburg.

In conclusion, we observed striking differences in the real-life management of cSSSI between two Nordic cities with similar healthcare structure and prevalence of antimicrobial resistance. Unnecessary Gram-negative antimicrobial coverage was common in both cities, although it was more common in Helsinki. Compared to mainly Infectious Disease Specialist-guided treatment in Gothenburg, the more frequent transfer from one ward to another in Helsinki was linked to longer antimicrobial therapy and hospital stay and to more frequent changes in antimicrobial treatment. This study suggests that infectious disease specialist-guided therapy and avoidance of transfers between wards may have a role in the optimizing of antimicrobial treatment. 
Funding: This study was sponsored by AstraZeneca Nordic-Baltic and funding in the form of a grant from Helsinki University Hospital (TYH2014212 and Y1209TUTKK).

Disclosure of interest: IJ has received financial support from Gilead for attending symposia. LH has received speaker's honoraria from Glaxo and Pfizer. TS has no conflict of interest. AJ has received speaker's honoraria from Astellas, MSD, OrionPharma, Ratiopharm and Unimedic Pharma and conference invitation from CLSBehring and has recent consultancies with MSD, Pfizer and Ratiopharm. 


\section{References}

1. Edelsberg J, Taneja C, Zervos M, et al. Trends in US hospital admissions for skin and soft tissue infections. Emerg Infect Dis. 2009;15:1516-8.

2. Hayward A, Knott F, Petersen I, et al. Increasing hospitalizations and general practice prescriptions for community-onset staphylococcal disease, England. Emerg Infect Dis. 2008;14:720-6.

3. Center for Drug Evaluation and Research, Food and Drug Administration. Guidance for industry: uncomplicated and complicated skin and skin structure infections—developing antimicrobial drugs for treatment. Washington, DC: Food and Drug Administration, US Department of Health and Human Services; 1998.

4. Karppelin M, Siljander T, Haapala AM, et al. Evidence of streptococcal origin of acute nonnecrotising cellulitis: a serological study. Eur J Clin Microbiol Infect Dis. 2015;34:669-72.

5. Jeng A, Beheshti M, Li J, et al. The role of beta-hemolytic streptococci in causing diffuse, nonculturable cellulitis: a prospective investigation. Medicine (Baltimore). 2010;89:217-26.

6. Elliott DC, Kufera JA, Myers RA. Necrotizing soft tissue infections. Risk factors for mortality and strategies for management. Ann Surg. 1996;224:672-83.

7. Citron DM, Goldstein EJ, Merriam CV, et al. Bacteriology of moderate-to-severe diabetic foot infections and in vitro activity of antimicrobial agents. J Clin Microbiol. 2007;45:2819-28.

8. Kilburn SA, Featherstone P, Higgins B, et al. Interventions for cellulitis and erysipelas. Cochrane Database Syst Rev. 2010;16:CD004299. doi(6):CD004299.

9. Stevens DL, Bisno AL, Chambers HF, et al. Practice guidelines for the diagnosis and management of skin and soft tissue infections: 2014 update by the Infectious Diseases Society of America. Clin Infect Dis. 2014;59:e10-52. 
10. Montravers P, Snauwaert A, Welsch C. Current guidelines and recommendations for the management of skin and soft tissue infections. Curr Opin Infect Dis. 2016;29:131-8.

11. Marwick C, Broomhall J, McCowan C, et al. Severity assessment of skin and soft tissue infections: cohort study of management and outcomes for hospitalized patients. J Antimicrob Chemother. 2011;66:387-97.

12. Zilberberg MD, Shorr AF, Micek ST, et al. Hospitalizations with healthcare-associated complicated skin and skin structure infections: impact of inappropriate empiric therapy on outcomes. J Hosp Med. 2010;5:535-40.

13. Jenkins TC, Sabel AL, Sarcone EE, et al. Skin and soft-tissue infections requiring hospitalization at an academic medical center: opportunities for antimicrobial stewardship. Clin Infect Dis. 2010;51:895-903.

14. Carratala J, Roson B, Fernandez-Sabe N, et al. Factors associated with complications and mortality in adult patients hospitalized for infectious cellulitis. Eur J Clin Microbiol Infect Dis. 2003;22:151-7.

15. Garau J, Ostermann H, Medina J, et al. Current management of patients hospitalized with complicated skin and soft tissue infections across Europe (2010-2011): assessment of clinical practice patterns and real-life effectiveness of antibiotics from the REACH study. Clin Microbiol Infect. 2013;19:E377-85.

16. Nathwani D, Eckmann C, Lawson W, et al. Pan-European early switch/early discharge opportunities exist for hospitalized patients with methicillin-resistant Staphylococcus aureus complicated skin and soft tissue infections. Clin Microbiol Infect. 2014;20:993-1000.

17. Eckmann C, Lawson W, Nathwani D, et al. Antibiotic treatment patterns across Europe in patients with complicated skin and soft-tissue infections due to meticillin-resistant Staphylococcus 
aureus: a plea for implementation of early switch and early discharge criteria. Int $\mathrm{J}$ Antimicrob Agents. 2014;44:56-64.

18. Jaakola S, Lyytikäinen O, Rimhanen-Finne R, et al. Infectious Diseases in Finland 2011. THL; 2012. Available at: http://urn.fi/URN:ISBN:978-952-245-662-5.

19. Johnson AP. Methicillin-resistant Staphylococcus aureus: the European landscape. J Antimicrob Chemother. 2011;66:iv43-8.

20. Skin and soft tissue infections (online). Current Care Guidelines. Working group appointed by the Finnish Medical Society Duodecim and the Finnish Dermatological Society. Helsinki: The Finnish Medical Society Duodecim; 2010. [accessed 11.03.2017] Available online at: www.kaypahoito.fi.

21. The Swedish guideline for management of skin and soft tissue infections. Läkemedelsverket and Strama; 2009 [accessed 11.03.2017]. Available at: https://lakemedelsverket.se/upload/halsooch-sjukvard/behandlingsrekommendationer/Ny\%20rekommendation\%20\%20Farmakologisk\%20behandling\%20av\%20bakteriella\%20hud\%20och\%20mjukdelsinfektioner\%20.pdf.

22. Jaaskelainen IH, Hagberg L, From J, et al. Treatment of complicated skin and skin structure infections in areas with low incidence of antibiotic resistance-a retrospective population based study from Finland and Sweden. Clin Microbiol Infect. 2016;22:383.e1,383.e10.

23. Zervos MJ, Freeman K, Vo L, et al. Epidemiology and outcomes of complicated skin and soft tissue infections in hospitalized patients. J Clin Microbiol. 2012;50:238-45.

24. Jenkins TC, Knepper BC, Moore SJ, et al. Antibiotic prescribing practices in a multicenter cohort of patients hospitalized for acute bacterial skin and skin structure infection. Infect Control Hosp Epidemiol. 2014;35:1241-50. 
25. Diabetes-related foot problems (online). Current Care Guidelines. A working group appointed by the Finnish Medical Society Duodecim, the Medical Advisory Board of the Finnish Diabetes Society, the Finnish Endocrine Society and the Finnish Dermatological Society. Helsinki: The Finnish Medical Society Duodecim, 2009 [accessed 11.03.2017]. Available online at: www.kaypahoito.fi.

26. ESAC-net database [Internet]. ECDC; 2017 [accessed 14.03.2017]. Available from: http://ecdc.europa.eu/en/healthtopics/antimicrobial-resistance-and-consumption/antimicrobialconsumption/esac-net-database/Pages/consumption-rates-by-country.aspx.

27. Forsblom E, Ruotsalainen E, Ollgren J, et al. Telephone consultation cannot replace bedside infectious disease consultation in the management of Staphylococcus aureus Bacteremia. Clin Infect Dis. 2013;56:527-35.

28. Jenkins TC, Knepper BC, Jason Moore S, et al. Comparison of the microbiology and antibiotic treatment among diabetic and nondiabetic patients hospitalized for cellulitis or cutaneous abscess. J Hosp Med. 2014;9:788-94.

29. Hepburn MJ, Dooley DP, Skidmore PJ, et al. Comparison of short-course (5 days) and standard (10 days) treatment for uncomplicated cellulitis. Arch Intern Med. 2004;164:1669-74.

30. Lipsky BA, Moran GJ, Napolitano LM, et al. A prospective, multicenter, observational study of complicated skin and soft tissue infections in hospitalized patients: clinical characteristics, medical treatment, and outcomes. BMC Infect Dis. 2012;12:227. 


\begin{tabular}{|c|c|c|c|c|}
\hline \multicolumn{2}{|l|}{ Patient characteristics } & $\begin{array}{l}\text { Helsinki } \\
(n=219)\end{array}$ & $\begin{array}{l}\text { Gothenburg } \\
\qquad(\mathrm{n}=241)\end{array}$ & P-value \\
\hline \multicolumn{2}{|l|}{ Male Gender } & $140(63.9 \%)$ & $140(58.1 \%)$ & $0.2145[a]$ \\
\hline \multirow[t]{4}{*}{ Age } & Mean (sd) & $58.6(17.5)$ & $62.9(18.5)$ & \\
\hline & Median & 60.0 & 63.0 & \\
\hline & Q1, Q3 & $44.0,74.0$ & $49.0,77.0$ & \\
\hline & Min, Max & 19,93 & 18,98 & $0.0117[\mathrm{~b}]$ \\
\hline \multirow[t]{4}{*}{ Number of co-morbidities } & 0 & $59(26.9 \%)$ & $53(22.0 \%)$ & \\
\hline & 1 & $83(37.9 \%)$ & $90(37.3 \%)$ & \\
\hline & 2 & $49(22.4 \%)$ & $71(29.5 \%)$ & \\
\hline & $\geq 3$ & $28(12.8 \%)$ & $27(11.2 \%)$ & $0.8614[c]$ \\
\hline \multicolumn{2}{|l|}{ AIDS / HIV infection } & $6(2.7 \%)$ & $1(0.4 \%)$ & $0.0631[\mathrm{~d}]$ \\
\hline \multicolumn{2}{|c|}{ Any disease with immune system impairment } & $5(2.3 \%)$ & $9(3.7 \%)$ & $0.2807[\mathrm{~d}]$ \\
\hline \multicolumn{2}{|l|}{ Cancer / Malignancy } & $14(6.4 \%)$ & $22(9.1 \%)$ & $0.4028[d]$ \\
\hline \multicolumn{2}{|l|}{ Chronic renal failure } & $25(11.4 \%)$ & $7(2.9 \%)$ & $0.0004[\mathrm{~d}]$ \\
\hline \multicolumn{2}{|l|}{ Congestive heart disease } & $10(4.6 \%)$ & $33(13.7 \%)$ & 0.0077 [d] \\
\hline \multicolumn{2}{|l|}{ Diabetes } & $109(49.8 \%)$ & 78 (32.4\%) & $<0.0001[\mathrm{~d}]$ \\
\hline \multicolumn{2}{|l|}{ Liver disease } & $11(5.0 \%)$ & $12(5.0 \%)$ & 0.7405 [d] \\
\hline \multicolumn{2}{|l|}{ Other relevant disease } & $30(13.7 \%)$ & 37 (15.4\%) & $0.5832[\mathrm{~d}]$ \\
\hline \multicolumn{2}{|l|}{ Other renal disease } & $2(0.9 \%)$ & $6(2.5 \%)$ & $0.2902[d]$ \\
\hline \multicolumn{2}{|l|}{ Respiratory disease } & $22(10.0 \%)$ & $12(5.0 \%)$ & $0.0273[\mathrm{~d}]$ \\
\hline \multicolumn{2}{|c|}{ Hospitalization within 3 months previous to the index visit } & $51(23.3 \%)$ & $33(13.7 \%)$ & $0.0235[\mathrm{~d}]$ \\
\hline \multicolumn{2}{|c|}{ Invasive surgery within 3 months previous to the index visit } & $41(18.7 \%)$ & $30(12.4 \%)$ & $0.1667[\mathrm{~d}]$ \\
\hline \multicolumn{2}{|c|}{ Treatment with antibiotic before diagnosis of cSSSI } & $53(24.2 \%)$ & $82(34.0 \%)$ & $0.0293[d]$ \\
\hline \multicolumn{5}{|c|}{$\begin{array}{l}\text { [a] P-value for Fisher's exact test for association between cities and the variable } \\
\text { [b] P-value for difference between cities (t-test, pooled variances) } \\
\text { [c] P-value for association between cities and the variable, controlling for age (Cochran-Mantel- } \\
\text { Haenszel (row mean scores differ)) }\end{array}$} \\
\hline \multicolumn{5}{|c|}{$\begin{array}{l}\text { [d] P-value for association between cities and the variable, controlling for age (Cochran-Mantel- } \\
\text { Haenszel (general association)) }\end{array}$} \\
\hline
\end{tabular}

Table 1. Demographics and characteristics of patients with complicated skin and skin structure infection in Helsinki and Gothenburg. 


\begin{tabular}{|c|c|c|c|c|}
\hline \multicolumn{2}{|l|}{ Disease characteristics } & $\begin{array}{l}\text { Helsinki } \\
(\mathrm{n}=219)\end{array}$ & $\begin{array}{c}\text { Gothenburg } \\
(\mathrm{n}=241)\end{array}$ & P-value \\
\hline \multicolumn{2}{|l|}{ Abscess } & $93(42.5 \%)$ & $90(37.3 \%)$ & $0.8536[\mathrm{~b}]$ \\
\hline \multicolumn{2}{|l|}{ Bite } & $1(0.5 \%)$ & $1(0.4 \%)$ & $0.9689[\mathrm{~b}]$ \\
\hline \multicolumn{5}{|l|}{ Burn } \\
\hline \multicolumn{2}{|l|}{ Cellulitis / fasciitis [a] } & 95 (43.4\%) & $98(40.7 \%)$ & $0.4417[\mathrm{~b}]$ \\
\hline \multicolumn{2}{|l|}{ Decubitus ulcer (pressure ulcer) } & $1(0.5 \%)$ & $13(5.4 \%)$ & $0.0022[\mathrm{~b}]$ \\
\hline \multicolumn{2}{|l|}{ Diabetic foot ulcer } & $24(11.0 \%)$ & $24(10.0 \%)$ & $0.7022[\mathrm{~b}]$ \\
\hline \multicolumn{2}{|l|}{ Diabetic leg ulcer } & $8(3.7 \%)$ & $13(5.4 \%)$ & $0.3976[\mathrm{~b}]$ \\
\hline \multicolumn{2}{|l|}{ Lesion: Other } & & $2(0.8 \%)$ & $0.1496[\mathrm{~b}]$ \\
\hline \multicolumn{2}{|l|}{ Lesion: Unknown } & & $4(1.7 \%)$ & $0.1475[b]$ \\
\hline \multicolumn{2}{|l|}{ Peripheral vascular disease ulcer } & $14(6.4 \%)$ & $39(16.2 \%)$ & $0.0208[b]$ \\
\hline \multicolumn{2}{|l|}{ Post-surgical wound } & $50(22.8 \%)$ & $29(12.0 \%)$ & $0.0026[\mathrm{~b}]$ \\
\hline \multicolumn{2}{|l|}{ Post-traumatic wound } & $22(10.0 \%)$ & $28(11.6 \%)$ & $0.5750[\mathrm{~b}]$ \\
\hline \multirow{4}{*}{$\begin{array}{l}\text { Number of days between symptoms start and } \\
\text { diagnosis }\end{array}$} & $<2$ days & 87 (39.7\%) & $43(17.8 \%)$ & \\
\hline & 2-7 days & $109(49.8 \%)$ & $121(50.2 \%)$ & \\
\hline & $>7$ days & $23(10.5 \%)$ & $67(27.8 \%)$ & \\
\hline & Missing & & $10(4.1 \%)$ & $<0.0001[c]$ \\
\hline \multirow[t]{2}{*}{ White blood cell count at the time of diagnosis } & $<4000 / \mathrm{mm} 3$ & $3(1.4 \%)$ & $2(0.8 \%)$ & $0.6083[\mathrm{~b}]$ \\
\hline & $>10000 / \mathrm{mm} 3$ & $193(88.1 \%)$ & $202(83.8 \%)$ & $0.1864[\mathrm{~b}]$ \\
\hline \multirow[t]{5}{*}{ Highest CRP per patient } & No. of obs. & 219 & 232 & \\
\hline & Mean (sd) & $229.1(116.7)$ & $216.0(140.0)$ & \\
\hline & Median & 221.0 & 200.0 & \\
\hline & Q1, Q3 & $143.0,303.0$ & $110.0,300.0$ & \\
\hline & Min, Max & 17,681 & 5,640 & $0.4854[\mathrm{~d}]$ \\
\hline \multicolumn{2}{|l|}{ Septic shock } & $2(0.9 \%)$ & $3(1.2 \%)$ & $0.8127[b]$ \\
\hline \multicolumn{2}{|l|}{ Blood pressure support } & $54(24.7 \%)$ & $76(31.5 \%)$ & $0.0514[\mathrm{~b}]$ \\
\hline \multicolumn{5}{|c|}{$\begin{array}{l}\text { [a] Patients not having abscess, diabetic foot ulcer, diabetic leg ulcer or peripheral vascular disease ulcer } \\
\text { [b] P-value for association between cities and the variable, controlling for age (Cochran-Mantel- } \\
\text { Haenszel (general association)) } \\
\text { [c] P-value for difference between cities, controlling for age (Wilcoxon rank sum test stratified by agegroup) }\end{array}$} \\
\hline \multicolumn{5}{|c|}{ [d] P-value for difference between cities, controlling for age (2-way ANOVA) } \\
\hline
\end{tabular}

Table 2. Disease characteristics of patients with complicated skin and skin structure infection in Helsinki and Gothenburg. 


\begin{tabular}{|l|c|c|c|}
\hline Initial microbiological diagnosis [a] & $\begin{array}{c}\text { Helsinki } \\
(\mathrm{n}=213)\end{array}$ & $\begin{array}{c}\text { Gothenburg } \\
(\mathrm{n}=219)\end{array}$ & P-value [c] \\
\hline Monomicrobial infections & $69(32.4 \%)$ & $148(67.6 \%)$ & $<0.0001$ \\
Staphylococci & $32(15 \%)$ & $74(33.8 \%)$ & $<0.0001$ \\
$\quad$ Methicillin Sensitive S. aureus (MSSA) & $27(12.7 \%)$ & $62(28.3 \%)$ & 0.0006 \\
Methicillin Resistant S. aureus (MRSA) & $2(0.9 \%)$ & $1(0.5 \%)$ & 0.4631 \\
Coagulase-negative staphylococci & $3(1.4 \%)$ & $11(5 \%)$ & 0.0233 \\
Streptococci & $23(10.8 \%)$ & $46(21 \%)$ & 0.0025 \\
Streptococcus pyogenes & $13(6.1 \%)$ & $27(12.3 \%)$ & 0.0182 \\
Streptococcus agalactiae & $2(0.9 \%)$ & $1(0.5 \%)$ & 0.4357 \\
Beta-hemolytic Streptococci & $8(3.8 \%)$ & $16(7.3 \%)$ & 0.1032 \\
Streptococcus pneumoniae & 0 & $2(0.9 \%)$ & 0.1154 \\
Enterococci & 0 & $2(0.9 \%)$ & 0.1468 \\
Enterobacteriacae & $7(3.3 \%)$ & $7(3.2 \%)$ & 0.5397 \\
Pseudomonas & $2(0.9 \%)$ & $2(0.9 \%)$ & 0.9390 \\
Other gramnegative bacteria & $1(0.5 \%)$ & $3(1.4 \%)$ & 0.6507 \\
Anaerobic bacteria & $2(0.9 \%)$ & $2(0.9 \%)$ & 0.8329 \\
Other microorganism & $2(0.9 \%)$ & $12(5.5 \%)$ & 0.0046 \\
Polymicrobial infections & $73(34.3 \%)$ & $29(13.2 \%)$ & $<0.0001$ \\
Only Gram-positive bacteria & $17(8 \%)$ & $16(7.3 \%)$ & 0.7344 \\
Only Gram-negative bacteria & $3(1.4 \%)$ & $1(0.5 \%)$ & 0.2567 \\
Mixed & $53(24.9 \%)$ & $12(5.5 \%)$ & $<0.0001$ \\
Negative & $48(22.5 \%)$ & $27(12.3 \%)$ & 0.0029 \\
Missing [b] & $23(10.8 \%)$ & $15(6.8 \%)$ & \\
\hline [a] Result from first test where blood culture and/or swab/needle aspiration & \\
[b] Diagnosis unknown, or missing dates so first test can't be defined exist & & \\
[c] P-value for association between cities and the variable, controlling for age (Cochran-Mantel- & \\
Haenszel (general association)) & & & \\
\hline Table 3. MicrobiOlOgil diag & \\
\hline
\end{tabular}

Table 3. Microbiological diagnosis of patients with complicated skin and skin structure infection in Helsinki and Gothenburg. 


\begin{tabular}{|c|c|c|c|c|}
\hline \multicolumn{2}{|l|}{ Management characteristics } & \multirow{2}{*}{$\begin{array}{c}\begin{array}{c}\text { Helsinki } \\
(\mathrm{n}=219)\end{array} \\
193\end{array}$} & \multirow{2}{*}{\begin{tabular}{|c|}
$\begin{array}{c}\text { Gothenburg } \\
(\mathrm{n}=241)\end{array}$ \\
225
\end{tabular}} & P-value \\
\hline Length of hospital stay, days & No. of obs. & & & \\
\hline & Mean (sd) & $29.0(41.6)$ & $15.2(22.1)$ & \\
\hline & Median & 17.0 & 11.0 & \\
\hline & Q1, Q3 & $8.0,32.0$ & $6.0,18.0$ & \\
\hline & Min, Max & 2,298 & 1,278 & $<0.0001[\mathrm{~d}]$ \\
\hline \multirow{5}{*}{$\begin{array}{l}\text { Number of wards the patient visited } \\
\text { during hospital stay [a] }\end{array}$} & No. of obs. & 219 & 232 & \\
\hline & 1 & $94(42.9 \%)$ & $196(84.5 \%)$ & \\
\hline & 2 & $68(31.1 \%)$ & $32(13.8 \%)$ & \\
\hline & 3 & $26(11.9 \%)$ & $4(1.7 \%)$ & \\
\hline & $\geq 4$ & $31(14.2 \%)$ & & $<0.0001[\mathrm{e}]$ \\
\hline \multirow{6}{*}{$\begin{array}{l}\text { Wards the patient visited during hospital } \\
\text { stay }\end{array}$} & Intensive Care Unit (ICU) & $41(18.7 \%)$ & $32(13.3 \%)$ & $0.2675[f]$ \\
\hline & Emergency Medicine Room (EMR) & $25(11.4 \%)$ & $9(3.7 \%)$ & $0.0036[f]$ \\
\hline & Medicine $[b]$ & $110(50.2 \%)$ & $81(33.6 \%)$ & $0.0001[\mathrm{f}]$ \\
\hline & Surgery & $140(63.9 \%)$ & $61(25.3 \%)$ & $0.0001[\mathrm{f}]$ \\
\hline & Infection & $54(24.7 \%)$ & $116(48.1 \%)$ & $0.0001[\mathrm{f}]$ \\
\hline & Other [c] & $19(8.7 \%)$ & $4(1.7 \%)$ & $0.0009[\mathrm{f}]$ \\
\hline \multirow{5}{*}{$\begin{array}{l}\text { Number of different antibiotic therapy } \\
\text { courses }\end{array}$} & No. of obs. & 219 & 238 & \\
\hline & Mean (sd) & $4.3(2.6)$ & $2.7(1.1)$ & \\
\hline & Median & 4.0 & 3.0 & \\
\hline & Q1, Q3 & $2.0,5.0$ & $2.0,3.0$ & \\
\hline & Min, Max & 1,18 & 1,8 & $<0.0001[\mathrm{~d}]$ \\
\hline \multirow[t]{5}{*}{ Overall treatment duration, days } & No. of obs. & 219 & 240 & \\
\hline & Mean (sd) & $42.8(59.9)$ & $17.3(28.7)$ & \\
\hline & Median & 29.0 & 12.0 & \\
\hline & Q1, Q3 & $16.0,44.0$ & $6.0,20.0$ & \\
\hline & Min, Max & 1,606 & 1,372 & $<0.0001[\mathrm{~d}]$ \\
\hline \multirow{5}{*}{$\begin{array}{l}\text { Any detected insufficient response or } \\
\text { treatment failure }[\mathrm{g}]\end{array}$} & Unplanned surgical drainage & $53(24.2 \%)$ & $72(29.9 \%)$ & $0.1195[\mathrm{f}]$ \\
\hline & $\begin{array}{l}\text { Treatment failure registered into } \\
\text { patient records by the treating } \\
\text { physician }\end{array}$ & $14(6.4 \%)$ & $8(3.3 \%)$ & $0.1030[f]$ \\
\hline & $\begin{array}{l}\text { No change or worsened clinical } \\
\text { situation after } 5 \text { days of treatment }\end{array}$ & 37 (16.9\%) & $20(8.3 \%)$ & $0.0052[\mathrm{f}]$ \\
\hline & Other & $1(0.5 \%)$ & $3(1.2 \%)$ & $0.5137[\mathrm{f}]$ \\
\hline & No & $137(62.6 \%)$ & $149(61.8 \%)$ & $0.8430[\mathrm{f}]$ \\
\hline \multicolumn{5}{|c|}{ [a] Can include same ward several times, patients can visit one ward more than once } \\
\hline \multirow{2}{*}{\multicolumn{5}{|c|}{$\begin{array}{l}\text { [c] Dermatology, Otorhinolaryngology, Obstetrics and Gynecology, Oncology } \\
\text { [d] P-value for difference between cities, controlling for age (2-way ANOVA) }\end{array}$}} \\
\hline & & Pulr & \\
\hline \multicolumn{5}{|c|}{$\begin{array}{l}\text { [e] P-value for association between cities and the variable, controlling for age (Cochran-Mantel- } \\
\text { Haenszel (row mean scores differ)) }\end{array}$} \\
\hline \multicolumn{5}{|c|}{$\begin{array}{l}\text { [f] P-value for association between cities and the variable, controlling for age (Cochran-Mantel- } \\
\text { Haenszel (general association)) }\end{array}$} \\
\hline
\end{tabular}

Table 4. Clinical management and use of resources in patients with complicated skin and skin structure infection in Helsinki and Gothenburg. 


\begin{tabular}{|c|c|c|c|c|c|c|}
\hline \multirow{2}{*}{$\begin{array}{l}\text { Antibiotic agent } \\
\text { No. of obs. }\end{array}$} & \multicolumn{2}{|c|}{ Initial therapy } & \multicolumn{2}{|c|}{ Subsequent therapy } & \multicolumn{2}{|c|}{ Discharge agents } \\
\hline & $\begin{array}{l}\text { Helsinki } \\
(\mathrm{n}=219)\end{array}$ & $\begin{array}{l}\text { Gothenburg } \\
(\mathrm{n}=239)\end{array}$ & $\begin{array}{l}\text { Helsinki } \\
(n=216)\end{array}$ & $\begin{array}{l}\text { Gothenburg } \\
\qquad(\mathrm{n}=216)\end{array}$ & $\begin{array}{l}\text { Helsinki } \\
(n=137)\end{array}$ & $\begin{array}{c}\text { Gothenburg } \\
(n=102)\end{array}$ \\
\hline Broad-spectrum & $58(26.5 \%)$ & $29(12.1 \%)$ & $46(21.3 \%)$ & $21(9.7 \%)$ & & $1(1.0 \%)$ \\
\hline Carbapenem & $51(23.3 \%)$ & $7(2.9 \%)$ & $38(17.6 \%)$ & $11(5.1 \%)$ & & \\
\hline Piperacillin-Tazobactam & $7(3.2 \%)$ & $22(9.2 \%)$ & $8(3.7 \%)$ & $10(4.6 \%)$ & & $1(1.0 \%)$ \\
\hline Cephalosporins & $151(68.9 \%)$ & $73(30.5 \%)$ & $65(30.1 \%)$ & $33(15.3 \%)$ & 80 (58.4\%) & $9(8.8 \%)$ \\
\hline Cefalexin & $2(0.9 \%)$ & & 40 (18.5\%) & & 79 (57.7\%) & \\
\hline Cefadroxil & & $1(0.4 \%)$ & & $9(4.2 \%)$ & & $8(7.8 \%)$ \\
\hline Cefuroxime & $139(63.5 \%)$ & $17(7.1 \%)$ & $16(7.4 \%)$ & $1(0.5 \%)$ & & \\
\hline Ceftriaxone & $10(4.6 \%)$ & & $8(3.7 \%)$ & & & \\
\hline Cefotaxim & & $55(23.0 \%)$ & & $23(10.6 \%)$ & & $1(1.0 \%)$ \\
\hline Ceftazidim & & & $1(0.5 \%)$ & & & \\
\hline Cefazolin & & & & & $1(0.7 \%)$ & \\
\hline Penicillins with staphylococcal effect & & $52(21.8 \%)$ & $9(4.2 \%)$ & 49 (22.7\%) & $8(5.8 \%)$ & $37(36.3 \%)$ \\
\hline Cloxacillin & & $41(17.2 \%)$ & $7(3.2 \%)$ & $13(6.0 \%)$ & & \\
\hline Flucloxacillin & & $10(4.2 \%)$ & & $34(15.7 \%)$ & & $33(32.4 \%)$ \\
\hline Dicloxacillin & & & & $1(0.5 \%)$ & & $1(1.0 \%)$ \\
\hline Betalactamase-stable Penicillin & & $1(0.4 \%)$ & & & & \\
\hline Amoxicillin-Clavulanic Acid & & & $2(0.9 \%)$ & $1(0.5 \%)$ & $8(5.8 \%)$ & $3(2.9 \%)$ \\
\hline Penicillins & $2(0.9 \%)$ & $51(21.3 \%)$ & $8(3.7 \%)$ & $29(13.4 \%)$ & $5(3.6 \%)$ & $18(17.6 \%)$ \\
\hline Benzylpenicillin & $2(0.9 \%)$ & $49(20.5 \%)$ & $4(1.9 \%)$ & $13(6.0 \%)$ & & $4(3.9 \%)$ \\
\hline Fenoxymethylpenicillin & & $1(0.4 \%)$ & $3(1.4 \%)$ & $14(6.5 \%)$ & $3(2.2 \%)$ & $12(11.8 \%)$ \\
\hline Ampicillin & & & $1(0.5 \%)$ & & & \\
\hline Amoxicillin & & $1(0.4 \%)$ & & $2(0.9 \%)$ & $2(1.5 \%)$ & $2(2.0 \%)$ \\
\hline Other & $8(3.7 \%)$ & $34(14.2 \%)$ & 88 (40.7\%) & 84 (38.9\%) & $86(62.8 \%)$ & $48(47.1 \%)$ \\
\hline Clindamycin & $4(1.8 \%)$ & $18(7.5 \%)$ & $13(6.0 \%)$ & $50(23.1 \%)$ & 25 (18.3\%) & $34(33.3 \%)$ \\
\hline Fluoroquinolone & $2(0.9 \%)$ & $4(1.7 \%)$ & $16(7.4 \%)$ & $10(4.6 \%)$ & 28 (20.4\%) & 7 (6.9\%) \\
\hline Metronidazole & & $3(1.3 \%)$ & $36(16.7 \%)$ & 15 (6.9\%) & $17(12.4 \%)$ & $4(3.9 \%)$ \\
\hline Vancomycin & & $1(0.4 \%)$ & $14(6.5 \%)$ & $1(0.5 \%)$ & & \\
\hline Linezolid & $1(0.5 \%)$ & & $1(0.5 \%)$ & & $3(2.2 \%)$ & \\
\hline Tigecyclin & & & $1(0.5 \%)$ & & & \\
\hline Co-trimoxazole & & $1(0.4 \%)$ & & $3(1.4 \%)$ & $2(1.5 \%)$ & \\
\hline Tobramycin & & $3(1.3 \%)$ & & $3(1.4 \%)$ & & \\
\hline Doxycyklin & & $2(0.8 \%)$ & & $1(0.5 \%)$ & & $2(2.0 \%)$ \\
\hline Fusidic Acid & & $1(0.4 \%)$ & & & $1(0.7 \%)$ & $1(1.0 \%)$ \\
\hline Netilmycin & & & $1(0.5 \%)$ & & & \\
\hline Fluconazole & & & $2(0.9 \%)$ & $1(0.5 \%)$ & $5(3.7 \%)$ & \\
\hline Anidulafungin & & & $1(0.5 \%)$ & & & \\
\hline Rifampicin & & & & & $1(0.7 \%)$ & \\
\hline Unknown & $1(0.5 \%)$ & $1(0.4 \%)$ & $3(1.4 \%)$ & & $4(2.9 \%)$ & \\
\hline
\end{tabular}

Table 5. Antimicrobial treatment of patients with complicated skin and skin structure infection in Helsinki and Gothenburg. 


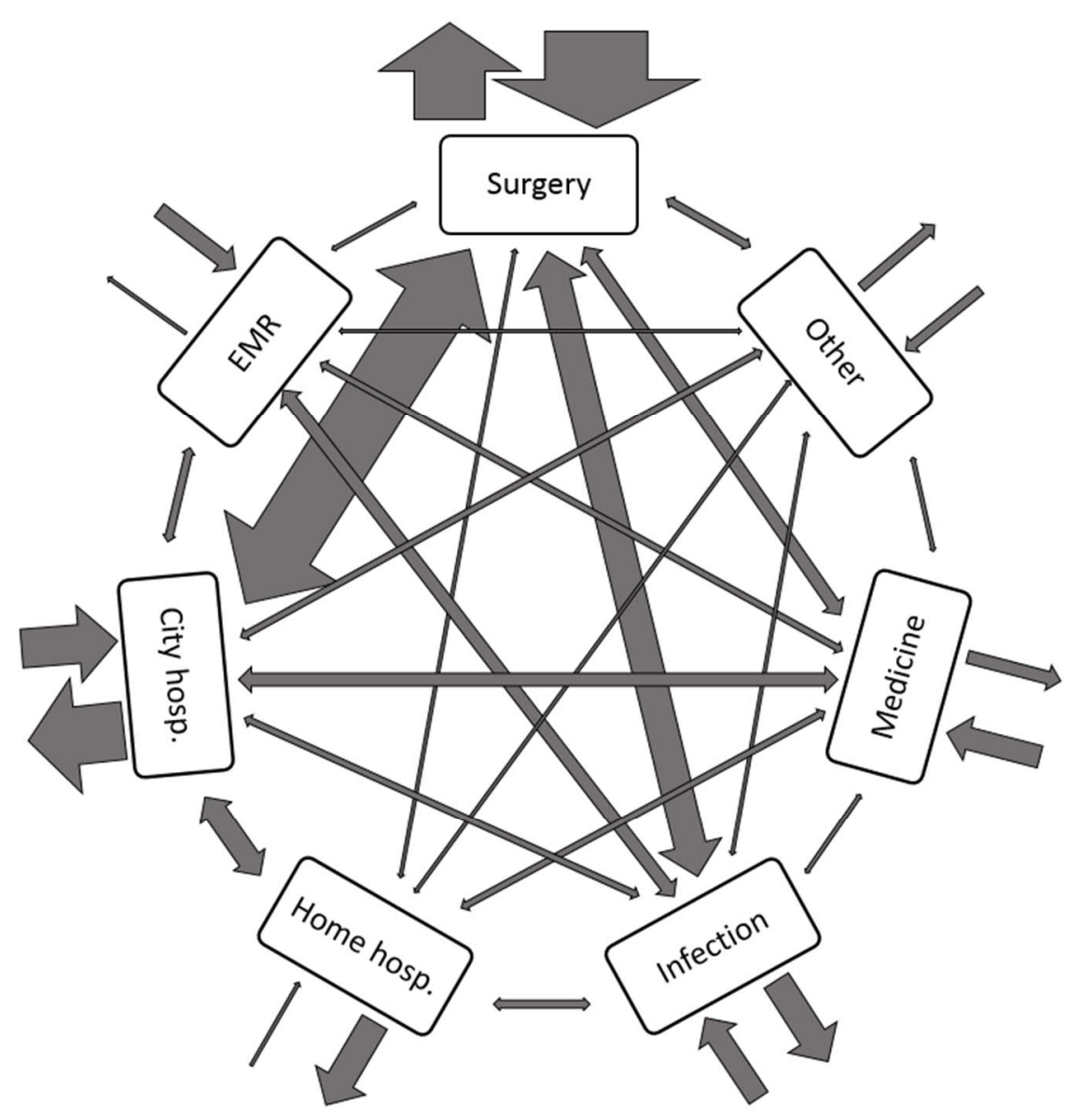

Line thickness of 10 patient transfers between clinics

Figure 1. The flow of patients with complicated skin and skin structure infections between wards during their hospital stay in Helsinki (left) and in Gothenburg (right). The thickness of arrow indicates the number of patient transfers between the wards. The arrows outside the circle pointing inside indicate the first ward the patient entered and the outward arrow the discharging ward. EMR = Emergency Medicine Room.

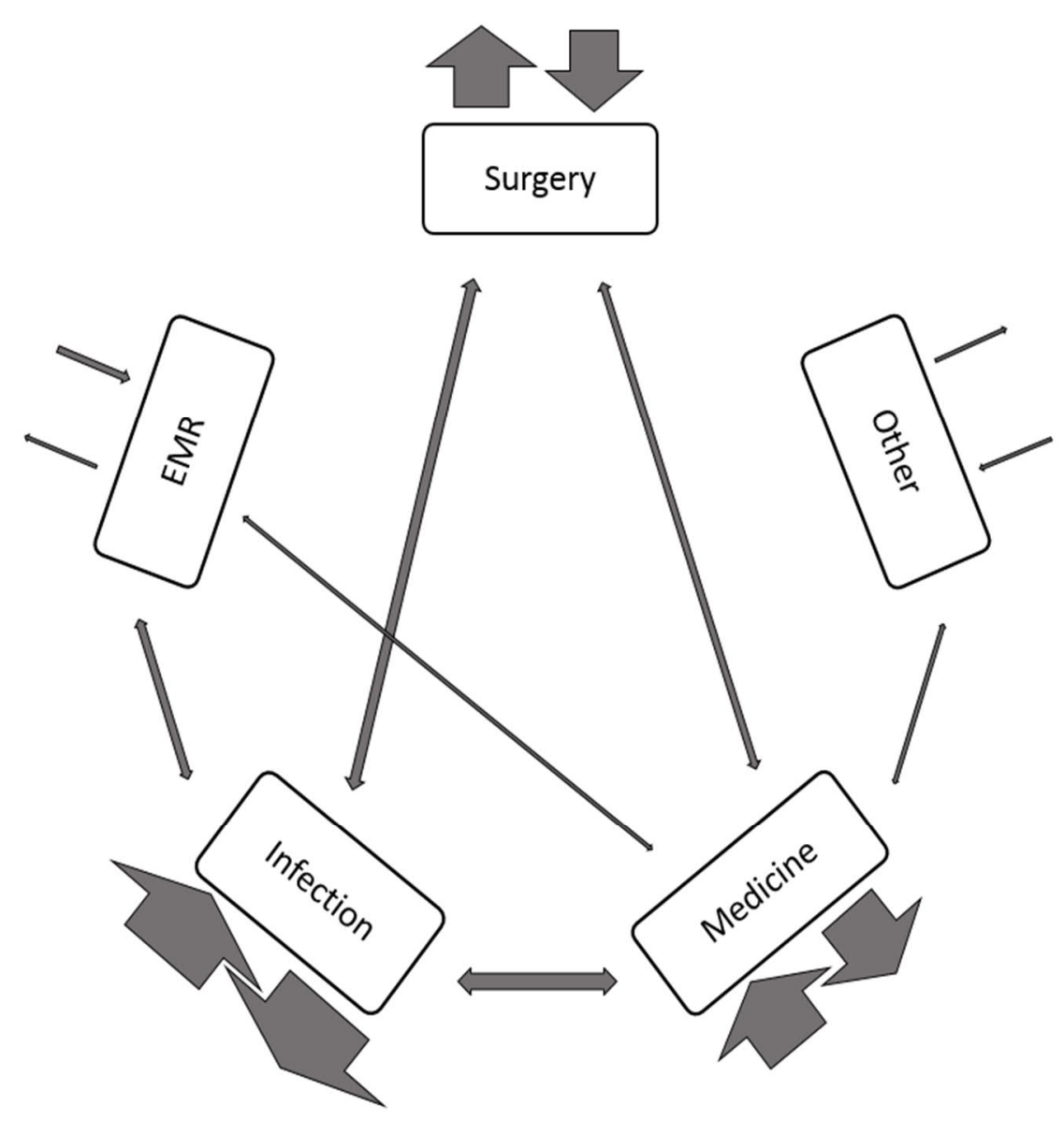

Line thickness of 10 patient transfers between clinics 